\title{
STUDY OF FOETAL NASAL BONE LENGTH DURING 15-38 WEEKS OF GESTATION IN WOMEN OF NORTHERN INDIA (U.P.) AND ITS COMPARISON WITH WESTERN AND OTHER ASIAN WOMEN
}

\author{
D. P. Gupta1, Ratna Prabha Gupta², D. K. Saxena ${ }^{3}$,Hem Prabha Gupta ${ }^{4}$,Zeeshan Zaidi ${ }^{5}$ \\ 1 Professor, Department of Radiology, Era's Lucknow Medical College, Lucknow. \\ ${ }^{2}$ Associate Professor, Department of Physiology, GCRGIMS, Lucknow. \\ ${ }^{3}$ Associate Professor, Department of Radiology, Era's Lucknow Medical College, Lucknow. \\ 4 Professor, Department of Obstetrics \& Gynaecology, Era's Lucknow Medical College, Lucknow. \\ 5Statistician Cum Lecturer, Department of Community Medicine, Era's Lucknow Medical College, Lucknow.
}

ABSTRACT

Foetal nasal bone length vary in different ethnic groups, its rate of growth in a particular group can be accurately measured. This increase in foetal nasal bone length can be used as a reference range for that particular group.

\section{OBJECTIVE}

This study is an attempt to evaluate a reference range of foetal nasal bone length from 15 wks. to full term in North Indian population and to find the difference with other ethnic groups during the same period of gestation.

\section{MATERIAL AND METHOD}

Pregnant women undergoing ultrasonography from 15 wks. till term with a single live foetus having no complication either in the foetus or mother were selected for the study. All parameters i.e. BPD, AC, FL, kidney length, nasal bone length measurements and their rate of growth were calculated and findings were compared with other authors.

\section{RESULTS}

The rate of growth of foetal nasal bone length during different weeks of gestation showed correlation described by the following equation NBL $=0.349 \mathrm{XGA}+0.440$ with goodness of fit estimate $\mathrm{R}^{2}=0.969$ with a constant $\mathrm{p}$ value $<0.0001$. There was a significant difference in length of foetal nasal bone length in different ethnic groups. Our results in North Indian population were similar to that of South Indian, Caucasians, Brazilian population, but very different from that of Chinese and Japanese population.

\section{CONCLUSION}

The data can be used in estimation of GA by NBL as the estimation of NBL is accurate and the increase per week of gestation shows a linear increase in Indian population.

\section{KEYWORDS}

Foetal Nasal Bone, Normal Range, North Indian Women.

HOW TO CITE THIS ARTICLE: Gupta DP, Gupta RP, Saxena DK, et al. Study of foetal nasal bone length during 15-38 weeks of gestation in women of Northern India (U.P.) and its comparison with Western and other Asian women. J. Evolution Med. Dent. Sci. 2016;5(61):4277-4279, DOI: 10.14260/jemds/2016/976

\section{INTRODUCTION \\ For ages the nose has been the symbol of family status, the longer the nose the higher the family status. Is the foetal nasal bone length different in different societies or the rate of growth different, leading to a smaller nose in Chinese, Japanese and a long nose in Caucasians in later life, The study would clear all doubts. It would also try to determine whether rate of growth in different weeks of gestation is the same in different ethnic groups and if it can be used to determine the gestation age accurately.}

\section{AIM AND OBJECTIVE}

To measure foetal nasal bone length from the early gestational period (15 weeks) to full term ( 38 weeks). To ascertain the

Financial or Other, Competing Interest: None.

Submission 03-04-2016, Peer Review 23-05-2016,

Acceptance 30-05-2016, Published 30-07-2016.

Corresponding Author:

Dr. D. P. Gupta,

MIG-2, Napier Road Part II,

LDA Colony, Thakurganj,

Lucknow-226003.

E-mail:dp_gupta2007@yahoo.co.in

DOI: $10.14260 /$ jemds $/ 2016 / 976$ rate of foetal nasal bone growth during gestation and to compare it with studies from other Western and Asian countries. To assess the incidence of small or absent nasal bone, as in Down's syndrome in North Indian population and to compare it with other studies.

The study would help in the early detection of Down's syndrome and would help in its screening by using a combination of nuchal translucency, free beta Human Chorionic Gonadotropins (hCG) and pregnancy associated plasma proteins-A (PAPP_A).

\section{MATERIAL AND METHOD}

All pregnant subjects between 15-38 weeks of gestation who were sent for routine ultrasonographic examination to the Department of Radiology at Era's Lucknow Medical College, Lucknow, between October 2011 to June 2015 were screened for BPD, FL, AC, foetal kidney length and foetal nasal bone length. Inclusion criteria in the study were, 1) Known LMP, 2) No foetal abnormality or pregnancy complication, 3) IUGR, 4) Any maternal disease. In each case, foetal measurements were taken by a single experienced ultrasonographer using a USG machine Elpro G E Logic 200 and a $3.5 \mathrm{MHz}$ sector transducer was used. Measurements of the foetal nasal bone were 
obtained from a strictly median sagittal plane of the foetal head that imaged. The foetal profile characterized by the nasal bone's synostosis, foetal lips and aligned maxilla and mandible was noted. An anechoic cartilaginous area between the midline of the frontal bone and the nasal bones can be recognized and identifies the nasal bridge, the hyperechogenic nasal bone synostosis can therefore accurately be measured. Care was taken to keep the angle of insonation to 45 or 135 degrees. Three independent measurements were obtained and averaged to obtain the final nasal bone length. A permanent record of the image was retained on a thermal print paper for future record.

Routine measurements of biparietal diameter, femur length and transverse abdominal diameters were obtained in standard plane. The scanning plane visualizes abnormalities including abnormal nose, micrognathia, enlarged tongue or absent nasal bridge. These profile images of the face are helpful in identification of foetuses with a family history of facial abnormalities. They also assist in accurate diagnosis of multiple malformation syndrome including Down's syndrome by showing additional markers such as protruding tongue, flat profile with small hypoplastic nose. Small hypoplastic nose has been described as a component of over 40 genetic syndrome, such as trisomy 21 and trisomy 18, Apert and de Lange Syndrome.

\section{RESULT}

2743 pregnant women were screened for nasal bone length measurements along with other foetal parameters including BPD, AC, FL and kidney length. Only singleton foetuses of pregnant women between gestational age from 15 wks. to 38 wks. were included in the study. Each patient contributed to only one set of measurements. Criteria for exclusion of the cases were any foetal abnormality, IUGR and any other disease in the pregnant women, i.e. diabetes, tuberculosis or any other disabling disease. Age of the pregnant women varied from 16 yrs. to 42 yrs. Number of cases between 30 yrs. - 42 yrs. of age were 219 . The nasal bone length increased significantly from $5.0 \mathrm{~mm}$ at 15 wks. to $13.8 \mathrm{~mm}$ at 38 wks., an increase of $171.7 \%$. The mean nasal bone length was $10.23 \mathrm{~mm}$ with an overall SD of 2.079 .

Linear regression analysis was performed for finding relationship between NBL and GA and it came out to be $\mathrm{NBL}=0.349 \times \mathrm{xGA}+0.440$ with goodness of fit estimate $\mathrm{R}^{2}=0.969$ ( $\mathrm{p}$ value $=0.0001$ ) as shown in scatter plot.

\section{Scatter Plot}

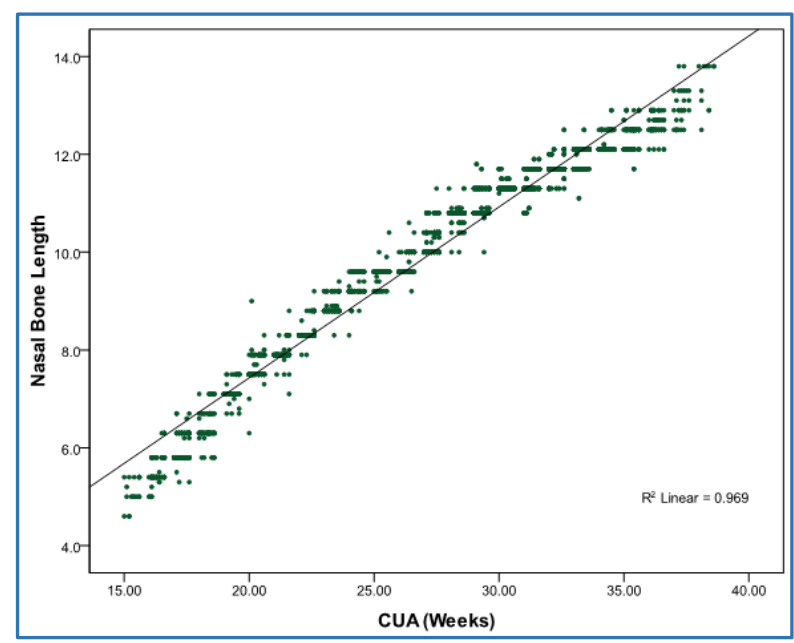

Showing Nasal Bone Length in Relation to CUA
The rate of increase of nasal bone length decelerates as the pregnancy progresses. The average increase was $63.04 \%$ between $15-20$ wks., $50.67 \%$ between $20-30$ wks. and only $10.62 \%$ growth above 31 wks. The overall increase in nasal bone length from $15-38$ wks. is $7.9 \mathrm{~mm}$ a growth rate of $171.7 \%$ (Table No. 1).

\begin{tabular}{|c|c|}
\hline Wks. & Rate of Increase (In \%) \\
\hline $15-20$ & 63.04 \\
\hline $20-30$ & 50.67 \\
\hline 31 above & 10.62 \\
\hline Overall & 171.74 \\
\hline Table 1: Showing \% Increase of Nasal Bone Length \\
\hline
\end{tabular}

The normal ranges are listed in Table No. 2 . The ranges $5^{\text {th }}$ $95^{\text {th }}$ percentiles for each gestational age are relatively narrow as shown in Table No. 2.

\begin{tabular}{|c|c|c|c|c|c|c|c|c|}
\hline \multirow[t]{2}{*}{$\begin{array}{c}\text { GA } \\
\text { (Weeks) }\end{array}$} & \multirow{2}{*}{\begin{tabular}{|c|}
$\begin{array}{c}\text { No. } \\
\text { of } \\
\text { Cases }\end{array}$ \\
\end{tabular}} & \multicolumn{7}{|c|}{$\begin{array}{c}\text { Percentiles for the Nasal Bone } \\
\text { Length (In mm) }\end{array}$} \\
\hline & & 5th & 10th & 25th & 50th & \begin{tabular}{|l|} 
75th \\
\end{tabular} & 90th & 95th \\
\hline 15 & 19 & 4.60 & 4.60 & 5.00 & 5.00 & 5.40 & 5.40 & \\
\hline 16 & 73 & 5.00 & 5.34 & 5.40 & 5.40 & 5.80 & 5.80 & 6.30 \\
\hline 17 & 91 & 5.80 & 5.80 & 5.80 & 5.80 & 6.30 & 6.30 & 6.42 \\
\hline 18 & 99 & 5.80 & 6.30 & 6.30 & 6.30 & 6.70 & 7.10 & 7.10 \\
\hline 19 & 93 & 6.87 & 7.10 & 7.10 & 7.10 & 7.10 & 7.50 & 7.50 \\
\hline 20 & 111 & 7.50 & 7.50 & 7.50 & 7.50 & 7.90 & 7.90 & 7.94 \\
\hline 21 & 90 & 7.67 & 7.90 & 7.90 & 7.90 & 7.90 & 8.00 & 8.30 \\
\hline 22 & 84 & 8.30 & 8.30 & 8.30 & 8.30 & 8.30 & 8.80 & 8.80 \\
\hline 23 & 74 & 8.80 & 8.80 & 8.80 & 8.80 & 9.20 & 9.20 & 9.20 \\
\hline 24 & 73 & 8.80 & 9.20 & 9.20 & 9.20 & 9.60 & 9.60 & 9.60 \\
\hline 25 & 77 & 9.20 & 9.2 & & 9.6 & 9.60 & & 3 \\
\hline 26 & 74 & 9.60 & 9.60 & 9.60 & 9.60 & 10.00 & 10.00 & 10.00 \\
\hline 27 & 132 & 10.00 & 10.00 & 10.00 & 10.25 & 10.40 & 10.80 & 10.80 \\
\hline 28 & 128 & 10.40 & 10.60 & 10.80 & 10.80 & 10.80 & 10.80 & 10.90 \\
\hline 29 & 162 & 10.80 & 10.80 & 10.80 & 11.30 & 11.30 & 11.30 & 11.30 \\
\hline 30 & 203 & 11.30 & 11.30 & 11.30 & 11.30 & 11.30 & 11.30 & 11.30 \\
\hline 31 & 262 & 11.30 & 11.30 & 11.30 & 11.30 & 11.70 & 11.70 & 11.70 \\
\hline 32 & 257 & 11.30 & 11.70 & 11.70 & 11.70 & 11.70 & 11.70 & 12.00 \\
\hline 33 & 227 & 11.70 & 11.70 & 11.70 & 12.10 & 12.10 & 12.10 & 12.10 \\
\hline 34 & 192 & 12.10 & 12.10 & 12.10 & 12.10 & 12.10 & 12.50 & 12.50 \\
\hline 35 & 112 & 12.10 & 12.10 & 12.10 & 12.50 & 12.50 & 12.64 & 12.90 \\
\hline 36 & 70 & 12.10 & 12.50 & 12.50 & 12.50 & 12.70 & 12.90 & 12.90 \\
\hline 37 & 29 & 12.50 & 12.50 & 12.50 & 12.90 & 13.30 & 13.30 & 13.80 \\
\hline 38 & 11 & 12.50 & 12.58 & 12.90 & 13.80 & 13.80 & 13.80 & \\
\hline & & 2.0 & WI & 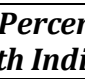 & 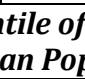 & ivas & 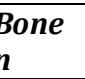 & \\
\hline
\end{tabular}

The mean nasal bone length at 15 wks. was $5.09 \mathrm{~mm}$, increasing gradually at the rate of $0.44 \mathrm{~mm}$ per week till 30 weeks, then the rate of growth decreased and finally by 35 wks. it stopped (Table No. 3).

\begin{tabular}{|c|c|c|c|c|c|}
\hline $\begin{array}{c}\text { GA } \\
\text { (Weeks) }\end{array}$ & Mean & SD & Mean-2SD & Mean+2SD & $\begin{array}{c}\text { Mean } \\
\text { Increase } \\
\text { (mm) }\end{array}$ \\
\hline 15 & 5.09 & .29 & 4.52 & 5.67 & - \\
\hline 16 & 5.53 & .29 & 4.96 & 6.10 & 0.44 \\
\hline 17 & 6.03 & .30 & 5.42 & 6.63 & 0.50 \\
\hline 18 & 6.47 & .33 & 5.81 & 7.13 & 0.44 \\
\hline 19 & 7.14 & .17 & 6.80 & 7.49 & 0.67 \\
\hline 20 & 7.66 & .28 & 7.09 & 8.22 & 0.52 \\
\hline 21 & 7.92 & .18 & 7.56 & 8.28 & 0.26 \\
\hline 22 & 8.38 & .21 & 7.95 & 8.80 & 0.46 \\
\hline 23 & 8.91 & .19 & 8.52 & 9.29 & 0.63 \\
\hline 24 & 9.29 & .25 & 8.80 & 9.79 & 0.38 \\
\hline 25 & 9.54 & .20 & 9.15 & 9.93 & 0.25 \\
\hline
\end{tabular}




\begin{tabular}{|c|c|c|c|c|c|}
\hline 26 & 9.76 & .23 & 9.29 & 10.23 & 0.22 \\
\hline 27 & 10.25 & .28 & 9.69 & 10.80 & 0.49 \\
\hline 28 & 10.77 & .16 & 10.44 & 11.10 & 0.52 \\
\hline 29 & 11.10 & .28 & 10.54 & 11.65 & 0.33 \\
\hline 30 & 11.31 & .05 & 11.21 & 11.41 & 0.21 \\
\hline 31 & 11.47 & .24 & 10.99 & 11.95 & 0.16 \\
\hline 32 & 11.70 & .16 & 11.39 & 12.02 & 0.23 \\
\hline 33 & 11.93 & .22 & 11.50 & 12.36 & 0.23 \\
\hline 34 & 12.16 & .15 & 11.85 & 12.47 & 0.23 \\
\hline 35 & 12.38 & .26 & 11.85 & 12.90 & 0.22 \\
\hline 36 & 12.59 & .21 & 12.17 & 13.01 & 0.21 \\
\hline 37 & 12.94 & .38 & 12.18 & 13.70 & 0.35 \\
\hline 38 & 13.41 & .49 & 12.44 & 14.38 & 0.47 \\
\hline Total & 10.24 & 2.08 & 6.08 & 14.40 & \\
\hline \multicolumn{5}{|c|}{ Table 3: Showing Mean and SD } \\
for the Nasal Bone Length (In mm) \\
\hline
\end{tabular}

\section{DISCUSSION}

This study gives a nasal bone reference range throughout the gestational period from 15 wks. to 38 wks. in North Indian population of Lucknow and its surrounding areas. The nasal bone is one of the facial features that has distinctly identified borders and therefore its length can be measured accurately in a standardized way.(1) Our figures of nasal bone length during different weeks of gestation have been compared with findings of other authors in Table No. 4. $(2,1,3,4,5)$

\begin{tabular}{|c|c|c|c|c|c|c|}
\hline \multirow{2}{*}{ GA } & \multicolumn{7}{|c|}{$\begin{array}{c}\text { North } \\
\text { Indian } \\
\text { This } \\
\text { Study }\end{array}$} & $\begin{array}{c}\text { South } \\
\text { Indian } \\
\text { Study }\end{array}$ & $\begin{array}{c}\text { Caucasian } \\
\text { Study }\end{array}$ & $\begin{array}{c}\text { Brazilian } \\
\text { Study }\end{array}$ & $\begin{array}{c}\text { Chinese } \\
\text { Study }\end{array}$ & $\begin{array}{c}\text { Japanese } \\
\text { Study }\end{array}$ \\
\hline 15 & 5.0 & & 4.3 & & 3.5 & 3.2 \\
\hline 16 & 5.4 & 5.9 & 4.7 & 5.9 & 4.1 & 3.5 \\
\hline 17 & 5.8 & 6.2 & 5.3 & 6.2 & 4.6 & 4.5 \\
\hline 18 & 6.3 & 6.5 & 5.7 & 6.5 & 5.0 & 4.9 \\
\hline 19 & 7.1 & 6.8 & 6.3 & 6.8 & 5.6 & 5.2 \\
\hline 20 & 7.5 & 7.0 & 6.7 & 7.0 & 5.8 & 5.8 \\
\hline 21 & 7.9 & 7.3 & 7.1 & 7.3 & 6.2 & 5.7 \\
\hline 22 & 8.3 & 7.6 & 7.5 & 7.6 & 6.7 & 6.6 \\
\hline 23 & 8.8 & 7.8 & 7.9 & 7.8 & & 7.2 \\
\hline 24 & 9.2 & & 8.3 & 8.0 & & \\
\hline 25 & 9.6 & & 8.5 & & & \\
\hline 26 & 9.6 & & 8.9 & & & \\
\hline 27 & 10.3 & & 9.2 & & & \\
\hline 28 & 10.8 & & 9.8 & & & \\
\hline 29 & 11.3 & & 9.8 & & & \\
\hline 30 & 11.3 & & 10.0 & & & \\
\hline 31 & 11.3 & & 10.4 & & & \\
\hline 32 & 11.7 & & 10.5 & & & \\
\hline 33 & 12.1 & & 10.8 & & & \\
\hline 34 & 12.1 & & 10.8 & & & \\
\hline 35 & 12.5 & & 11.0 & & & \\
\hline 36 & 12.5 & & & & & \\
\hline 37 & 12.5 & & & & & \\
\hline 38 & 12.7 & & & & & \\
\hline \multicolumn{7}{|c|}{ Table 4: Comparison of Nasal Bone Length } \\
in Indian Population with Other Population \\
\hline
\end{tabular}

Table No. 4 gives comparative values of nasal bone length in foetuses of North Indian and South Indian.(2) Caucasian.(1), Brazilian.(3), Chinese.(4) and Japanese.(5) population.

From the chart we have observed that the measurements of nasal bone length in North Indian population are very close to the findings of South Indian population and also Caucasian population. But Chinese and Japanese population shows smaller figures. Nraphut et al(6) have also reported smaller figures in Thai population as compared to our figures of North Indian population.

In our study of 2743 cases, we were unable to find even a single case of hypoplasia of nasal bone. Sonek et al(1) have reported incidence of absent nasal bone at 11-14 wks. gestational age in 3 cases out of 603 cases (0.5\%). In African Caribbean population at $10.4 \%$, Asian at $6.8 \%$ and white population at $2.8 \%$. Mid-second trimester foetal nasal bone measurements in healthy Chinese population was shorter than in White and Black population. Bundeppa et al(2) have also observed that race and ethnicity have an impact on foetal bone length.

Sonek et al(1) have reported an increased incidence of nasal bone hypoplasia in Afro-Caribbean population as compared to Caucasian $8.8 \%$ vs $5 \%$. Guis et al(7) have not reported any case of hypoplasia of foetal nasal bone in their Caucasian population in 376 cases that they studied. Bunduki et al(3) studied foetal nasal bone length in women in the age group of 35-45 yrs. and found hypoplasia of nasal bone length (Down's Syndrome) in $1.35 \%$ of their population. In our study of 406 cases above maternal age 30 yrs., we did not find a single case of hypoplasia of foetal nasal bone.

Foetal nasal bone measurements done in a strict sagittal plane are easily measured and are reproducible and are very consistent with gestational age are our observations in this study and therefore this study can be used as a reference. The high variability of foetal nasal bone length within different races is observed and therefore a reference range is necessary for each ethnic race.

\section{REFERENCES}

1. Sonek JD, McKenna D, Webb D, et al. Nasal bone length throughout gestation: normal ranges based on 3537 foetal ultrasound measurements. Ultrasound Obstet Gynecol 2003;21:152-5.

2. Narayani BH, Radhakrishnan P. Mid-second trimester measurement of nasal bone length in the Indian population. The journal of obstetrics and Gynecology of India 2013;63(4):256-9.

3. Bunduki V, Ruano R, Miguelez J, et al. Foetal nasal bone length: reference range and clinical application in ultrasound screening for trisomy 21. Ultrasound Obstet Gynecol 2003;21(2):156-60.

4. Chen M, Lee CP, Leung KY, et al. Pilot study on mid-second trimester examination of foetal nasal bone in Chinese population. Prenat Diag 2004;24(2):87-91.

5. Kanagawa T, Fukuda H, Kinugasa Y, et al. Mid-second trimester measurement of foetal nasal bone length in Japanese population. J Obstet Gynecol Res 2006;32(4):403-7.

6. Nraphut B, Uerpairojkit B, Chaithongwatthana S, et al. Nasal bone hypoplasia in trisomy 21 at 15 to 24 weeks gestation in a high risk Thai population. J Med Assoc Thia 2006;89(7):911-7.

7. Guis F, Ville $Y$, Vincent $Y$, et al. Ultrasound evaluation of the length of the foetal nasal bones throughout gestation. Ultrasound Obstet Gynecol 1995;5(5):304-7. 